\title{
A Influência do Fator de Vibração Térmica na Densidade Eletrônica de Cristais Bidimensionais
}

The influence of thermal factor on the electron density for two dimensional crystals

\author{
Plinio Delatorre ${ }^{1,2}$ e Walter Filgueira de Azevedo Junior ${ }^{1,3 *}$ \\ ${ }^{1}$ Departamento de Física, Instituto de Biociências, Letras e Ciências Exatas, UNESP, \\ São José do Rio Preto, SP 15054-000 \\ (http://www.biocristalografia.df.ibilce.unesp.br) \\ ${ }^{2}$ Centro Universitário de Votuporanga, \\ Votuporanga, SP, 15500-030, Brasil \\ ${ }^{3}$ Center for Applied Toxinology, CEPID-FAPESP \\ Av. Vital Brasil, 1500, São Paulo-SP, 05503-900, Brasil
}

Recebido em 23/01/2001. Manuscrito revisado em 31/05/2001. Aceito em 20/06/2001

\begin{abstract}
Este trabalho mostra o efeito da vibração térmica na densidade eletrônica de cristais bidimensionais, usando o programa Mathematica. É apresentado um modelo de cristal simples para ajudar no ensino de conceitos básicos relacionados à cristalografia.
\end{abstract}

This work shows the effect of thermal vibration on the electron density for two dimensional crystals, using the program Mathematica. It is presented a simple crystal model to help on teaching the basic concepts related to crystallography.

\section{Introdução}

O presente trabalho é parte do esforço contínuo, que o grupo de biocristalografia do Departamento de Física da Unesp - São José do Rio Preto, vem realizando com o objetivo de contribuir para melhoria do ensino de cristalografia, principalmente no que se refere ao uso da técnica de difração de raios $\mathrm{X}$ para a resolução de estruturas moleculares.[1]

Diversos programas específicos para cristalografia representam a densidade eletrônica de cristais de macromoléculas biológicas [2], contudo o uso desses programas avançados não tem como objetivo o ensino, levando o estudante de cristalografia muitas vezes a usar recursos sem ter noção da base física do modelo que está observando.

A visualização do efeito da vibração térmica na densidade eletrônica de um cristal bidimensional, em muito ajuda na fixação deste conceito, e deixa claro a sua importância na resolução de estruturas moleculares.

O objetivo deste trabalho é utilizar o programa Mathematica para a simulação do efeito da vibração térmica, em cristais bidimensionais, para facilitar o entendimento deste conceito no ensino de cristalografia.

\section{Introdução à Cristalografia}

É comum encontrarmos no dia-a-dia materiais na forma cristalina, e de uma maneira geral, os cristais sempre exerceram fascínio sobre as pessoas, principalmente pela sua beleza. O estudo das superfícies desses materiais é por si só interessante, mas o estudo cristalográfico vai além, procurando desvendar a estrutura cristalina, ou seja, como as moléculas estão arranjadas no cristal.

Com o objetivo de conhecer a estrutura cristalina, a cristalografia usa a técnica de difração de raios $\mathrm{X}$ que consiste, basicamente, em incidir-se raios $\mathrm{X}$, sobre o cristal e colher informações sobre os raios difratados em um filme fotográfico ou placa de imagem. No experimento a estrutura molecular e o arranjo das moléculas determinam a intensidade dos raios difratados [3].

\section{Fator de Espalhamento Atômico}

O fator de espalhamento atômico $(f)$ de um átomo depende de seu número de elétrons na nuvem eletrônica

\footnotetext{
*Autor para correspondência: Rua Cristovão Colombo, 2265, Jd. Nazareth, UNESP, Departamento de Física, São José do Rio Preto, SP, 15054-000
} 
(densidade eletrônica). Na "International Table for XRay Crystallography" pode ser encontrado como este se comporta em função de $\frac{\operatorname{sen} \theta}{\lambda}$. Neste trabalho estamos interessados em saber qual é o efeito da vibração térmica sobre o fator de espalhamento atômico. Tal fator é freqüentemente modificado pela introdução do fator de vibração térmica, que afeta diretamente as intensidades das reflexões no experimento de difração de raios $\mathrm{X}$, causando perdas no poder de espalhamento de cada átomo. A intensidade da vibração depende basicamente da temperatura, da massa do átomo e das forças ou ligações que o mantém em uma dada posição.

Considerando que a vibração atômica é isotrópica, isto é, as componentes da vibração são iguais em todas as direções, podemos dizer, então, que o fator de espalhamento atômico sofrerá uma redução em função da vibração térmica, sendo portanto modificado pela equação $e^{-B\left(\sin ^{2} \theta\right) / \lambda^{2}}$. Podemos escrever o fator de espalhamento atômico como sendo

$$
f=f_{0} e^{-B\left(\sin ^{2} \theta_{h k}\right) / \lambda^{2}},
$$

onde $\theta_{h k}$ é ângulo de espalhamento, $f_{0}$ é o poder de espalhamento de um dado átomo a uma dada reflexão, $\lambda$ é o comprimento de onda e $B$ é o fator de vibração térmica que está diretamente relacionado com a amplitude quadrática média $\left(\overline{u^{2}}\right)$ da vibração atômica, sendo dado por [4]

$$
B_{j}=8 \pi^{2} \overline{u^{2}} \text {. }
$$

\section{Fator de Estrutura}

O fator de estrutura $F(h k l)$ de um cristal pode ser escrito em termos de uma somatória sobre todas as contribuições individuais do espalhamento de cada átomo presente na cela unitária, dependendo do posicionamento dos mesmos na cela unitária, ou seja,

$$
F(h k l)=\sum_{j=1}^{n} f_{j} \exp \left(2 \pi i h x_{j}+2 \pi i k y_{j}+2 \pi i l z_{j}\right),
$$

onde $f_{j}$ é o fator de espalhamento atômico descrito na equação (1); $x_{j}, y_{j}$ e $z_{j}$ são as coordenadas fracionárias do átomo $(j)$ na cela unitária e $h k l$ são os índices de reflexão.

O cálculo do fator de estrutura, da forma apresentada acima, considera que os átomos sofrem vibrações constantes em torno de uma posição de equilíbrio.

Para o caso de um modelo centro-simétrico bidimensional a parte imaginária da equação (3) é cancelada. Então o fator de estrutura será uma combinação de termos reais dependentes de coseno dada por

$$
F(h k)=2 \sum_{j=1}^{n} f_{j} \cos \left[2 \pi\left(h x_{j}+k y_{j}\right)\right]
$$

onde os fatores de espalhamento atômicos possuem dependência direta das reflexões $h$ e $k$ [5].

\section{Densidade Eletrônica}

A densidade eletrônica indica a presença de átomos em determinadas posições da cela unitária, representando a estrutura do cristal. Sendo conhecido o fator de estrutura para todas as reflexões, então a densidade eletrônica pode ser determinada em qualquer ponto $x y z$ da cela unitária [6].

A densidade eletrônica de um cristal é dada por

$\rho(x y z)=\frac{1}{V} \sum_{h} \sum_{k} \sum_{l} \vec{F}(h k l) \exp [-2 \pi i(h x+k y+l z)]$

onde $V$ é o volume da cela unitária.

Para cristais bidimensionais centro-simétricos, pelo motivos expostos no cálculo do fator de estrutura, a expansão de Fourier da densidade eletrônica será dada por

$$
\rho(x y)=\frac{2}{A} \sum_{h} \sum_{k} F(h k) \cos [2 \pi(h x+k y)]
$$

onde $h$ e $k$ são inteiros sobre os quais a série é somada e $A$ é a área da cela unitária.

\section{Método}

O programa Mathematica foi usado para simular o efeito da vibração térmica na densidade eletrônica do cristal, de maneira que pudéssemos visualizar as mudanças ocorridas nos picos de densidade eletrônica e nas curvas de níveis referentes a cada valor atribuído ao fator de vibração térmica.

\section{Modelo}

O modelo usado neste trabalho é um cristal hipotético bidimensional (na direção $x y$ ) da cadeia lateral do aminoácido fenilalanina (Fig.1). O comprimento da cela unitária $(L)$ é de $17 \AA$ em ambas as direções, com átomos posicionados conforme a tabela 1 .

Tabela 1. Posições dos átomos do modelo na cela unitária com suas devidas coordenadas fracionárias.

\begin{tabular}{|c|c|c|c|c|}
\hline Átomos & $\mathrm{X}(\AA)$ & $\mathrm{Y}(\AA)$ & $\mathrm{X} / \mathrm{L}$ & $\mathrm{Y} / \mathrm{L}$ \\
\hline$C_{1}$ & 3,0419 & 2,855 & 0,178935 & 0,167941 \\
$C_{2}$ & 1,8338 & 3,5525 & 0,107871 & 0,208971 \\
$C_{3}$ & 1,8338 & 4,9475 & 0,107871 & 0,291029 \\
$C_{4}$ & 3,0419 & 5,645 & 0,178935 & 0,332059 \\
$C_{5}$ & 4,25 & 4,9475 & 0,25 & 0,291029 \\
$C_{6}$ & 4,25 & 3,5525 & 0,25 & 0,208971 \\
$C_{7}$ & 3,0419 & 7,145 & 0,178935 & 0,420294 \\
\hline
\end{tabular}




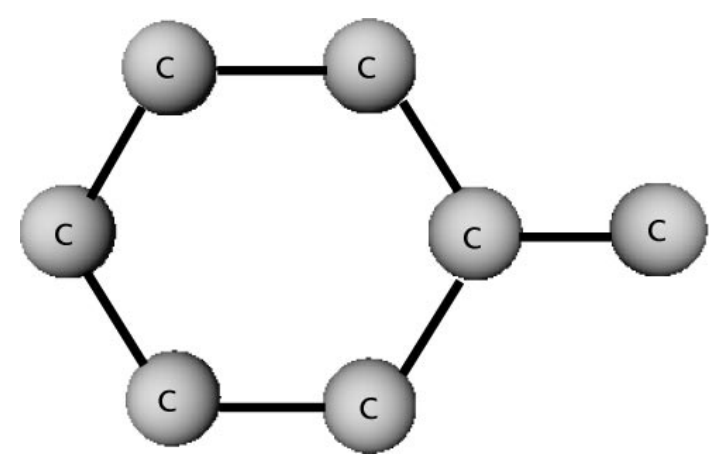

Figura 1. Cristal hipotético bidimensional da cadeia lateral do aminoácido fenilalanina.

\section{Resultados e Discussão}

Utilizando-se o comprimento de onda referente à radiação do $\mathrm{CuK}_{\alpha}(\lambda=1.5418 \AA)[7]$ e admitindo que a cela unitária é simétrica, de acordo com a natureza periódica da estrutura, foram gerados mapas de densidades eletrônicas com valores diferentes do fator de vibração térmica $\left(B_{j}\right)$, conforme Figs. 2, 3, 4. Os resultados mostram, de maneira clara, o efeito degradante da vibração térmica na intensidade de cada um dos picos do mapa de densidade eletrônica, que passaram de bem definidos para $B=0$ a quase indefinido em $B$ $=4 \AA^{2}$. Este resultado era esperado pois a vibração térmica provoca uma perda na intensidade dos raios $\mathrm{X}$ espalhados e esta é diretamente proporcional ao módulo do fator de espalhamento atômico ao quadrado $I \alpha|F|^{2}$.

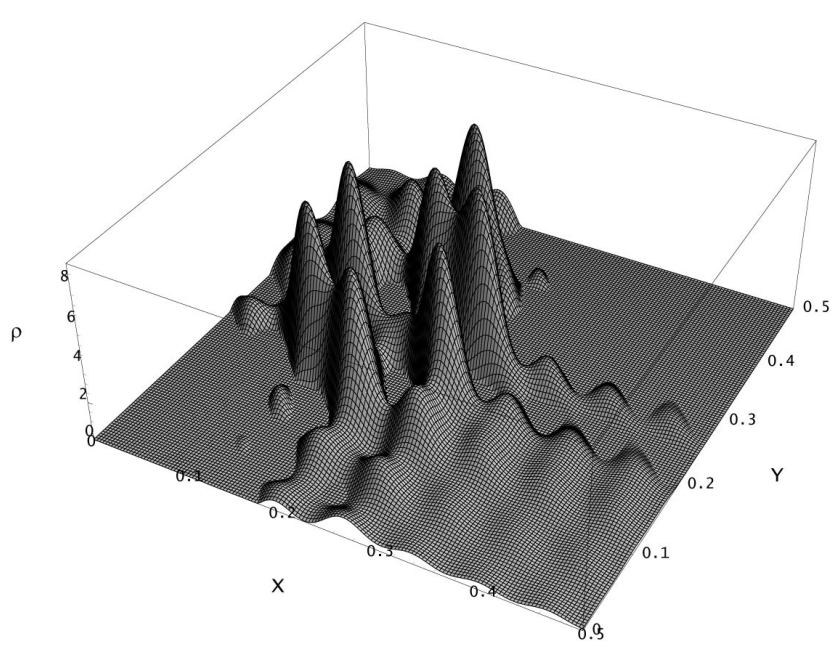

Figura 2. Mapa de Densidade Eletrônica $(B=0)$.

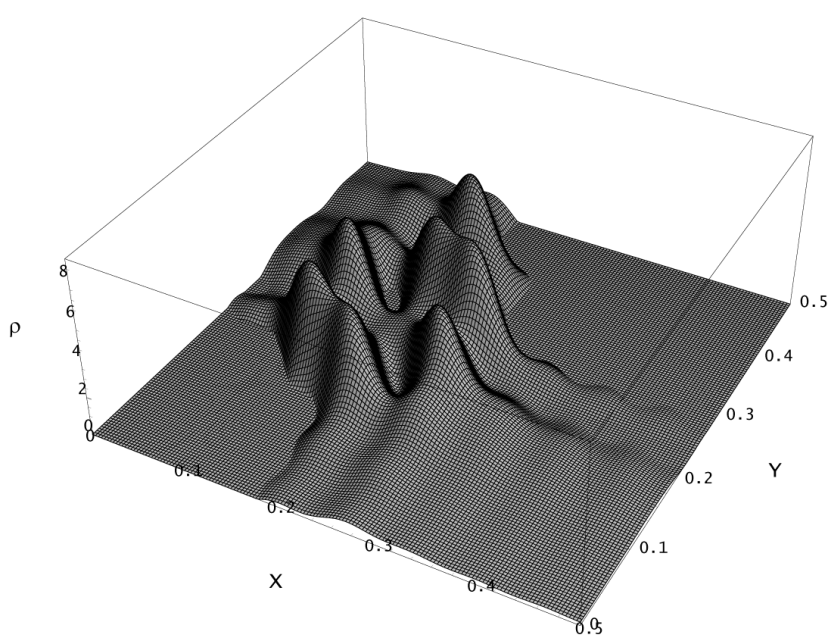

Figura 3. Mapa de Densidade Eletrônica $\left(B=2 \AA^{2}\right)$.

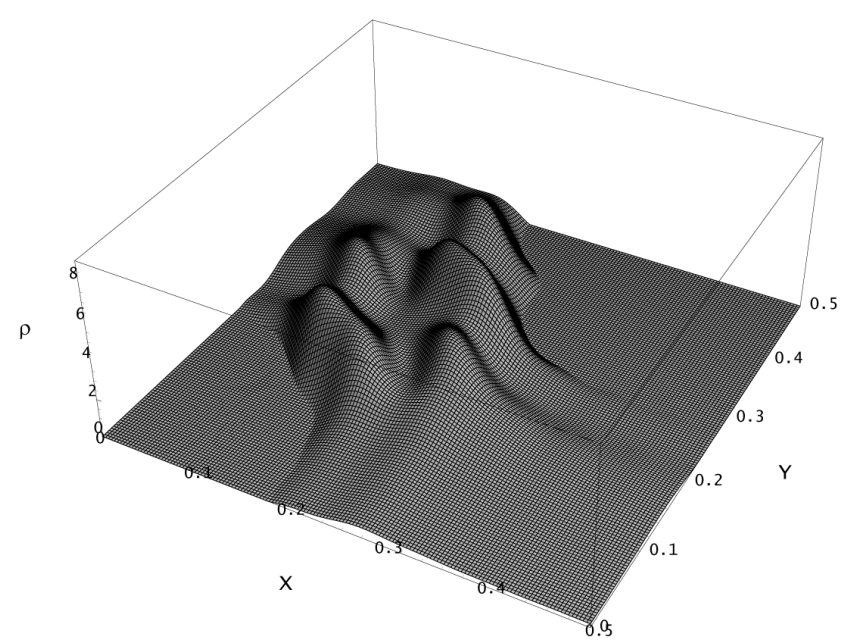

Figura 4. Mapa de Densidade Eletrônica $\left(B=4 \AA^{2}\right)$.

Através da análise dos picos no mapa de densidade eletrônica pode ser observada a geometria da molécula. Os picos de maior intensidade são provenientes do posicionamento de um átomo, os de menor são devidos a ruídos que aparecem em função da limitação do número de termos na série de Fourier. Portanto, quando observamos a Fig. 2, temos uma visão clara da disposição geométrica de cada um dos átomos que compõem a cela unitária; o mesmo não ocorre na Fig. 4.

Para o mapa de densidade eletrônica com $B$-fator zero foram geradas duas figuras de curvas de níveis (Fig.5 e Fig.6), com o objetivo facilitar a visualização das disposições geométricas dos átomos. Na Fig. 5 as posições atômicas são os pontos que são circundados por um maior número de curvas de níveis, as demais curvas encontradas na figura são relativas a ruídos. A Fig. 6 mostra a sobreposição do modelo no gráfico de contorno, tornando a visualização mais fácil. 


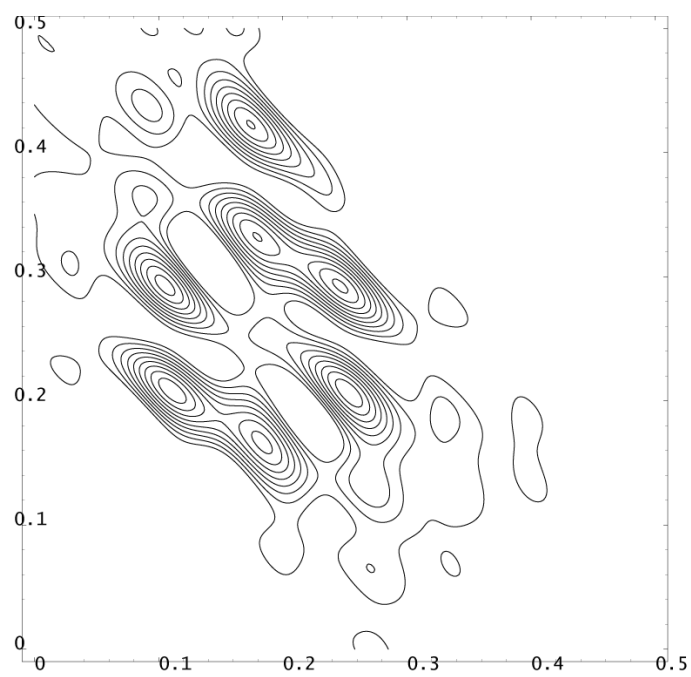

Figura 5. Gráfico de Contorno do Modelo $(\mathrm{B}=0)$.

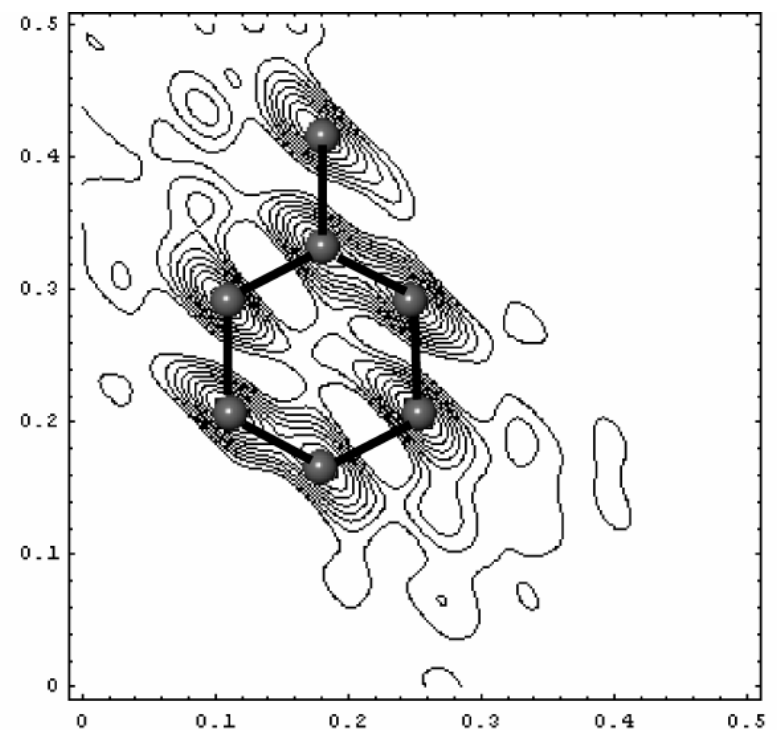

Figura 6. Sobreposição do modelo no gráfico de contorno do Modelo $\left(\mathrm{B}=2 \AA^{2}\right)$.

\section{Conclusões}

As representações gráficas das simulações das densidades eletrônicas permitiram uma fácil identificação do efeito da vibração térmica, o que enfatiza a importância desta no estudo estrutural de macromoléculas biológicas. O objetivo principal da cristalografia por difração de raios $\mathrm{X}$ é determinar as posições atômicas na cela unitária, processo este feito a partir da interpretação dos mapas de densidade eletrônica. A partir desta simulação fica claro o efeito dos fatores de vibração térmica na análise de mapas de densidade eletrônica. Regiões do mapa de densidade eletrônica que apresentam alto fator de vibração térmica dificultam em muito a interpretação dos mesmos [8-10]. O modelo, aqui apresentado, permite que novas simulações sejam feitas variando-se as posições atômicas e os fatores de vibração térmica. Os arquivos utilizados nas simulações aqui apresentadas estão disponíveis no endereço: http://www.biocristalografia.df.ibilce.unesp.br/ $\mathrm{xtal} /$ simul/vbef2.html

\section{Agradecimentos}

Agradecemos ao professor Dr. Johnny Rizzieri Olivieri pela colaboração na realização deste trabalho. Este trabalho não seria possível sem as contribuições financeiras da Capes, Fapesp e da diretoria do IBILCEUNESP. Walter Filgueira de Azevedo Jr. é pesquisador

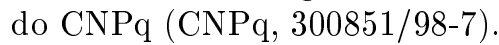

\section{References}

[1] Delatorre, P., Fadel, V., de Azevedo, W. F. Jr., Simulação de densidade eletrônica para cristais uni e bidimensionais, Revista Brasileira de Ensino de Física, Vol. 23(1), 63-73 (2001).

[2] McRee, D. E., Practical Protein Crystallography, Academic Press, Inc., San Diego (1993).

[3] Sands, Donald E., Introduction to Crystallography, Dover Publications,Inc., New York (1993).

[4] G.H. Stout and L.H. Jensen, X-ray Structure Determination, Second Edition, John Wiley \& Sons, New York (1989).

[5] J. Drenth, Principles of protein X-ray crystallography, Editora Springer-verlag, Boston (1994).

[6] T.L. Blundell and L.N. Johnson, Protein Crystallography, Academic Press, London (1976).

[7] International Tables For X-Ray Crystallography (1974). Vol. III. The Kynoch Press, Birmingham, England.

[8] de Azevedo, W. F. Jr., Mueller-Dieckmann, H-. J., Schulze-Gahmen, U., Worland, P. J., Sausville, E. and Kim, S-. H. Structural basis for specificity and potency of a flavonoid inhibitor of human CDK2, a cell cycle kinase. Proc. Natl. Acad. Sci. USA. Vol. 93, 2735-2740 (1996).

[9] Kim. S. -H., Schulze-Gahmen, U., Brandsen, J. \& de Azevedo, W. F., Jr., Structural basis for chemical inhibition of CDK2. Progress in Cell Cycle Research, Vol. 2, 137-145. Chapter 14. (Meijer, L., Guidet, S. \& Vogel, L., eds.) Plenum Press, New York, USA. (1996).

[10] de Azevedo, W. F., Jr., Leclerc, S., Meijer, L., Havlicek, L., Strnad, M. and Kim, S. -H., Inhibition of cyclindependent kinases by purine analogues: crystal structure of human cdk2 complexed with roscovitine.. Eur. J. Biochemistry, 243, 518-526. (1997). 